\title{
Peningkatan Ekonomi Rumah Tangga Dengan Pengolahan Pisang
}

\author{
Denny Putri Hapsari ${ }^{1}$, Dian Maulita ${ }^{2}$, Nana Umdiana ${ }^{3}$ \\ ${ }^{1}$ Akuntansi, Universitas Serang Raya, Serang, Indonesia \\ ${ }^{2}$ Akuntansi, Universitas Serang Raya, Serang, Indonesia \\ ${ }^{3}$ Akuntansi, Universitas Serang Raya, Serang, Indonesia \\ Email: 11denny.putri@rocketmail.com,2maulita.dian@gmail.com , \\ 3nanaumdianaunsera@gmail.com
}

\begin{abstract}
Abstrak
Desa Kasunyatan merupakan salah satu desa yang berada di Kota Serang yang penduduknya rata-rata bermata pencaharian dengan cara bertani dan berkebun. Salah satu hasil Sumber Daya Alam di Desa Kasunyatan yang paling berlimpah adalah pisang. Beberapa jenis pisang yang tumbuh di Desa Kasunyatan diantaranya adalah pisang uli, pisang kepok, pisang tanduk, pisang nangka,dll. Jenis-jenis pisang tersebut memiliki nilai ekonomi rendah jika dijual segar. Untuk meningkatkan nilai jual dari buah pisang tersebut perlu adanya diversifikasi pengolahan buah pisang salah satunya dengan pengolahan pisang crispy. Metode yang digunakan pada pengabdian ini dengan melakukan ceramah dan diskusi kewirausahaan serta pelatihan praktek pembuatan pisang crispy pada Desa Kasunyatan. Tujuan dari pelaksanaan kegiatan ini adalah agar masyarakat Desa Kasunyatan memiliki penghasilan tambahan sehingga dapat meningkatkan ekonomi rumah tangga yang pada akhirnya dapat meningkatkan kesejahteraan warga Desa Kasunyatan.
\end{abstract}

Kata Kunci: Pendapatan, Diversifikasi Pisang, Kewirausahaan

\section{PENDAHULUAN}

Pembangunan ekonomi yang tangguh adalah pembangunan ekonomi yang berbasis potensi local, masyarakat menyadari potensi yang dimilikinya dan mereka dapat mengembangkan potensi tersebut hingga menjadi keunggulan lokal (Sunandar, Sumarsono, Djum, Benty, \& Nurjanah, n.d.). Ekonomi kerakyatan sebagai salah satu teori pembanding dari teori ekonomi capital menghendaki adanya peran aktif masyarakat dalam pengembangan kegiatan perekonomian yang real. Peran aktif tersebut pada akhirnya akan menjadi kekuatan tersendiri sehingga tatanan perekonomian rakyat tahan terhadap terpaan krisis ekonomi global. Pembangunan ekonomi berbasis lokal dilakukan dengan cara meningkatkan nilai jual produk lokal sehingga mampu meningkatkan pendapatan masyarakat. Upaya ini dilakukan untuk memperkuat dukungan pada programprogram reguler penanganan kemiskinan dan penciptaan lapangan kerja.

Dalam Upaya pengembangan masyarakat Indonesia yang merata, adil dan makmur tidak hanya menjadi tanggung jawab pemerintah semata. Secara proporsional tugas ini diemban pula oleh seluruh komponen bangsa lainnya, termasuk didalamnya masyarakat yang bersangkutan itu sendiri maupun oleh lapisan masyarakat lain yang secara sosial ekonomi berkemampuan relative lebih baik.

Provinsi Banten memiliki kekayaan alam yang tak terbatas yang menjadi modal bagi para pelaku ekonomi menjalankan usaha-usaha ekonomi. Sejauh ini, masih banyak kekayaan alam yang belum sepenuhnya dapat dikelola dan dirasakan manfaatnya bagi mayarakat wilayah Banten. 
Jumlah penduduk yang besar dan pertumbuhan yang tinggi serta penyebaran penduduk yang tidak merata ditambah kualitas penduduk yang relatif masih rendah merupakan salah satu masalah yang dihadapi Banten dalam pembangunan regional. Oleh karena itu, hal pertama dalam pembangunan regional diorientasikan kepada pencapaian insan manusia dengan tingkat kesadaran dan kesejahteraan secara merata diberbagai daerah khususnya di daerah Banten.

Pada masa kini secara keseluruhan pihak pemerintah menitikberatkan pada usaha meningkatkan aktifitas pembangunan di sektor perkampungan yang mempunyai nilai strategis dalam konteks pembangunan regional karena kenyataannya sebagian besar penduduk yang memiliki jiwa gotong royong dan kekeluargaan yang kuat bermukim di perkampungan yang merupakan potensi sumber-sumber manusiawi, disamping potensi sumber-sumber kekayaan alam yang masih jarang tersentuh.

Desa Kasunyatan merupakan salah satu desa yang berada di wilayah Kota Serang. Desa kasunyatan berada di dataran landai dengan keadaan topografi $\pm 500-700$ meter dari permukaan air laut di Kecamatan Kasemen, Serang - Banten. Berjarak $\pm 8,8 \mathrm{~km}$ dari pusat Kota Serang. Sebagian besar mata pencaharian penduduk Desa Kasunyatan adalah bertani dan berkebun dengan penghasilan relative rendah. Salah satu hasil sumber daya alam yang paling melimpah adalah pisang. Beberapa jenis pisang banyak tumbuh di Desa Kasunyatan Kecamatan Kasemen Kota Serang diantaranya adalah pisang uli, pisang kepok, pisang tanduk, pisang nangka, dll. Jenis-jenis pisang tersebut memiliki nilai ekonomi rendah jika dijual segar. Untuk meningkatkan nilai jual dari buah pisang tersebut perlu adanya upaya diversifikasi pengolahan buah pisang agar dapat meningkatkan harga jual dari buah pisang tersebut (Ari, 2016).

Buah pisang adalah salah satu jenis komoditi holtikultura dalam kelompok buah-buahan yang memiliki nilai sosial dan ekonomi cukup tinggi bagi masyarakat Indonesia pada umumnya dan Desa Kasunyatan pada khususnya. Manfaat buah pisang yang begitu besar bagi tubuh membuat pisang memiliki peluang usaha yang besar jika bisa diolah menjadi produk yang inovatif (Nurainy, Hidayati, Koesoemawardani, \& Suroso, 2017). Salah satunya adalah pisang crispy. Pisang crispy merupakan pengolahan buah pisang yang mengembangkan makanan tradisional yaitu pisang goreng yang sudah populer di masyarakat. Dalam produksinya pisang crispy digoreng dengan tepung yang renyah dan disajikan dengan menambahkan topping diatasnya seperti keju, coklat atau susu.

Diharapkan dengan adanya inovasi dari produk buah pisang menjadi pisang crispy ini dapat meningkat nilai tambah dari buah pisang tersebut sehingga bisa meningkatkan pendapatan bagi warga Desa Kasunyatan Kecamatan Kasemen Kota Serang.

\section{METODE PELAKSANAAN}

Metode pelaksanaan terdiri dari beberapa tahapan yakni sebagai berikut :

1. Perencanaan dan Persiapan

2. Pelaksanaan

\section{HASIL DAN PEMBAHASAN}

Metode pelaksanaan terdiri dari beberapa tahapan yakni sebagai berikut :

\section{Perencanaan dan Persiapan}

Tahapan persiapan dan perencanaan dimulai dari melakukan survey dan wawancara kepada masyarakat Desa Kasuyatan untuk memperoleh informasiinformasi terkait keadaan ekonomi, dan potensi desa. Berdasarkan hasil survey diketahui masyarakat Desa Kasuyatan memiliki hasil perkebunan yaitu pisang, yang hasil panennya dijual kepada para konsumen langsung dan pedagang pasar dengan harga yang sangat murah. Untuk meningkatkan nilai jual dari buah pisang 
tersebut maka dilakukan diversifikasi pengolahan buah pisang menjadi pisang crispy dengan tujuan meningkatkan nilai jual dari buah pisang tersebut.

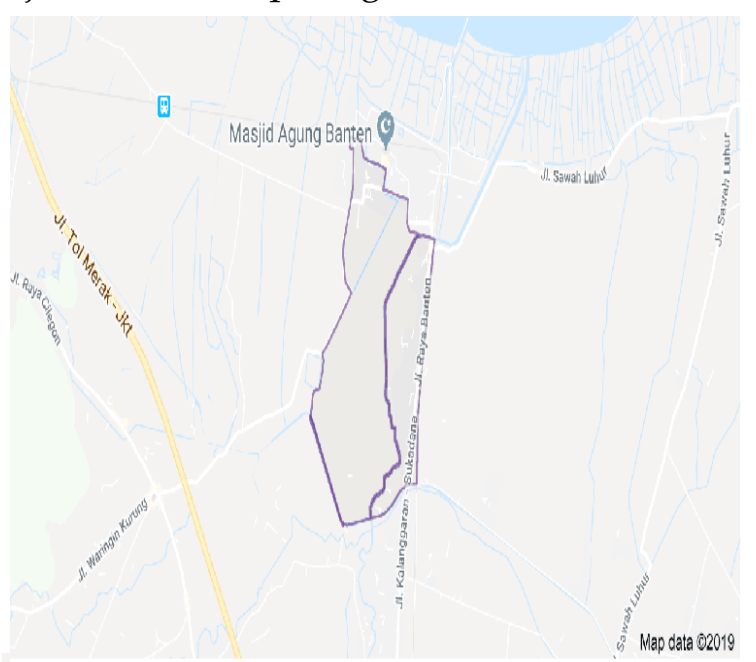

Gambar 1, Peta Lokasi Pengabdian

setelah dilakukan survey lokasi pengabdian langkah selanjutnya adalah melakukan koordinasi dengan pemerintah setempat baik RT, RW dan kelurahan untuk merencanakan kegiatan selanjutnya yaitu memberikan pengetahuan berwirausaha dalam bentuk pelatihan pembuatan produk kreatif yaitu mengolah buah pisang menjadi pisang crispy

\section{Pelaksanaan}

Pelaksanaan kegiatan menggunakan metode Entrepereneurship Education yang memberikan pendidikan berwirausaha bagi masyarakat, dengan menggunakan beberapa tahapan sebagai berikut :

a. Tahap observasi, melakukan pengamatan secara langsung ke lahan masyarakat Desa Kasuyatan untuk melihat hasil perkebunan pisang.

b. Wawancara, melakukan pertemuan dengan masyarakat sekitar yang memiliki hasil tanaman pisang. c. Mengadakan seminar wirausaha bagi masyarakat Desa Kasuyatan Kecamatan Kasemen Kota Serang

d. Mengadakan pelatihan pembuatan produk pisang menjadi pisang crispy

\section{HASIL DAN PEMBAHASAN}

\section{Seminar Wirausaha}

Pelaksanaan pengabdian yang pertama adalah dengan mengadakan seminar kewirausahaan di Desa Kasunyatan. Metode yang digunkan dalam seminar kewirausahaan adalah dengan memberikan ceramah dan diskusi mengenai kewirausahaan. Tujuan dari pelaksanaan kegiatan ini adalah agar warga Desa Kasunyatan memiliki pengetahuan dan wawasan mengenai kewirausahaan.

Kegiatan seminar wirausaha dilaksanakan di aula Balai Desa Kasunyatan yang dihadiri oleh warga Desa Kasunyatan serta unsur pemerintah desa seperti Ketua RT, Ketua RW dan Kepala Desa Kasunyatan. Kegiatan ini banyak mendapatkan perhatian dan dukungan dari masyarakat setempat, dimulai dari pemberian izin pelaksanaan kegiatan di aula Balai Desa Kasunyatan Kecamatan Kasemen dan mendorong masyarakat untuk mengikuti acara ini. Hal ini menunjukkan bahwa tingginya minat masyarakat Desa Kasunyatan untuk meningkatkan perekonomiannya dengan menjadi pelaku wirausaha.

Diharapkan dengan adanya seminar kewirausahaan ini warga Desa Kasunyatan memiliki motivasi untuk meningkatkan perekonomiannya dengan cara berwirausaha. 


\section{Pelatihan Praktek Produksi}

Pelatihan praktek produksi ini dilakukan di sekitar balai Desa Kasunyatan dengan menggunakan pendekatan bimbingan teknis, dimana para peserta dibimbing secara intensif. Langkah-langkah pembuatan pisang crispy adalah sebagai berikut :

a. Menyediakan bahan-bahan yang diperlukan

Bahan utama :

- Pisang uli matang

- Tepung terigu

- Tepung tapioka

- Tepung beras

- Garam

- Bubuk vanili

- Gula

- Air

Bahan Tambahan (Topping) :

- Keju

- Mesis

- Susu kental manis

b. Kupas pisang kemudian belah menjadi dua

c. Campur tepung terigu, tepung tapioka, tepung beras dan bubuk vanili secukupnya.

d. Tambahkan air sedikit demi sedikit hingga membentuk adonan yang cukup encer.

e. Tambahkan garam dan gula secukupnya, koreksi rasa jangan sampai terlalu asin atau manis.

f. Celupkan buah pisang yang telah dikupas kedalam adonan tepung kemudian goreng dengan menggunakan api sedang (jangan terlalu panas atau sekedar hangat)

g. Goreng pisang hingga berwarna kuning keemasan lalu pastikan bagian luarnya renyah dan bagian dalamnya matang sempurna.

h. Angkat pisang yang telah matang.

i. Taburkan keju, mesis, dan susu kental manis diatasnya sebagai toppingnya

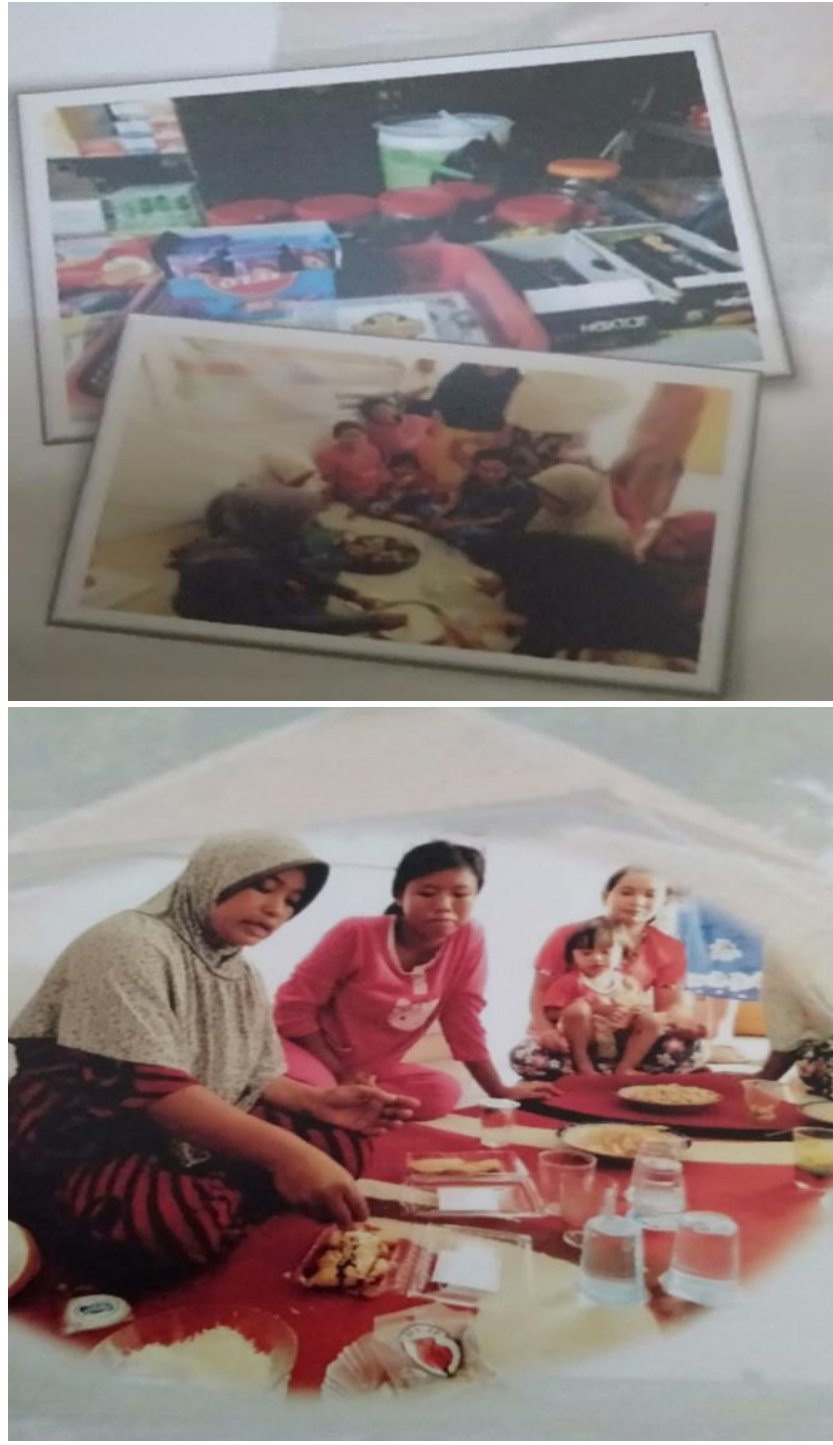

Gambar 2, Pelatihan Praktek produksi pisang crispy

\section{Pelatihan Desain Kemasan}

Pada proses pelaksanaan pelatihan desain kemasan metode yang digunakan adalah aplikatif serta penggunaan bahan baku yang mudah didapat agar pengetahuan dan teknik pengemasan yang diperoleh pada pelatihan tersebut mudah diterapkan oleh para peserta dalam kehidupan sehari-hari. pemberdayaan kreativitas masyarakat melalui program seperti ini secara luas diharapkan dapat meningkatkan kesejahteraan masyarakat. 


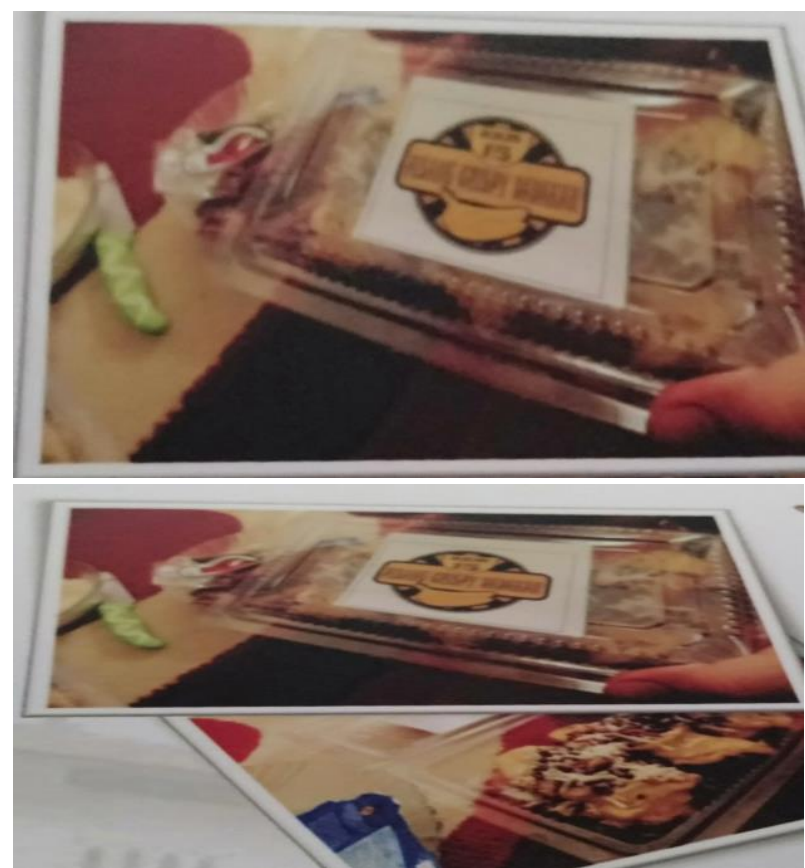

Gambar 3, Desain Kemasan Pisang Crispy

\section{Ucapan Terima Kasih}

Ucapan terima kasih kami sampaikan kepada pihak-pihak terkait:

1. Rektor Universitas Serang Raya yang telah memberikan ijin untuk melaksanakan kegiatan pengabdian masyarakat ini.

2. Dekan Fakultas Ekonomi dan Bisnis yang telah memberikan ijin dan dukungan dalam pelaksanaan kegiatan pengabdian masyarakat.

3. Ketua LPPM dan Kabag Pengabdian Masyarakat Universitas Serang Raya Kepada Rektor Universitas Serang Raya dan Dekan Fakultas Ekonomi dan Bisnis

4. Kepala Desa Kasuyatan beserta jajarannya yang telah memberikan ijin dan dukungan sehingga kegiatan ini dapat berjalan dengan baik.

5. Masyarakat Desa Kasuyatan atas partisipasi, antusiasme yang tinggi dan semangatnya untuk mengikuti kegiatan pengabdian ini.

\section{KESIMPULAN DAN SARAN}

\section{Kesimpulan}

Tingginya antusiasme masyarakat yang terlibat dalam kegiatan ini dapat kami simpulkan bahwa kegiatan pengabdian masyarakat di Desa Kasunyatan Kecamatan Kasemen melalui pelatihan pembuatan pisang crispy memberikan dampak yang nyata dan tepat guna.

Lebih luas lagi, dengan adanya pelatihan pengolahan pisang menjadi pisang crispy beserta pengemasannya dapat menunjang masyarakat untuk memiliki tambahan penghasilan guna meningkatkan kesejahteraan masyarakat khususnya di Desa Kasunyatan Kecamatan Kasemen Kota serang.

\section{Saran}

Program serupa diharapkan dapat dilaksanakan kedalam kelompok usaha mandiri di daerah yang berbeda khususnya di Provinsi Banten. Sehingga kegiatan ini dapat memberikan manfaat yang lebih luas serta mendukung program Nasional pemberdayaan masyarakat madani. Selain itu, dengan pemberdayaan kreativitas masyarakat melalui program seperti ini secara luas diharapkan dapat meningkatkan kesejahteraan masyarakat.

\section{DAFTAR REFERENSI}

Ari, A. (2016). Pisang pada pembuatan banana muffin dan tepung pisang pada pembuatan. Tugas Akhir Fakultas Teknik Universitas Negeri Yogyakarta.

Nurainy, F., Hidayati, S., Koesoemawardani, D., \& Suroso, E. (2017). Penyuluhan dan pelatihan pengolahan sale pisang kelompok usaha bersama aisyah di desa 
sukajawa kecamatan bumi ratu nuban kabupaten lampung tengah. SAKAI SAMBAYAN-Jurnal Pengabdian Kepada Masyarakat, (2012), 11-13.

Sunandar, A., Sumarsono, R. B., Djum, D., Benty, N., \& Nurjanah, N. (n.d.). Aneka Olahan Pisang Sebagai Upaya Meningkatkan Nilai Jual Pisang dan Pendapatan Masyarakat. 8-15.

Soetarjo. (2014). Penulisan artikel ilmiah. Dalam Sardi, B. dan Warsidi, Z. (Editor). Menulis artikel untuk jurnal pengabdian kepada masyarakat. Semarang: Cemerlang Press. 